\title{
Insecticide resistance of Anopheles sinensis and An. vagus in Hainan Island, a malaria-endemic area of China
}

Qian Qin ${ }^{1,2}$, Yiji Li ${ }^{1}$, Daibin Zhong ${ }^{3}$, Ning Zhou ${ }^{1}$, Xuelian Chang ${ }^{3}$, Chunyuan Li ${ }^{1}$, Liwang Cui ${ }^{4}$, Guiyun Yan ${ }^{3}$ and Xiao-Guang Chen ${ }^{1 *}$

\begin{abstract}
Background: Malaria is one of the most important public health problems in Southeast Asia, including Hainan Island, China. Vector control is the main malaria control measure, and insecticide resistance is a major concern for the effectiveness of chemical insecticide control programs. The objective of this study is to determine the resistance status of the main malaria vector species to pyrethroids and other insecticides recommended by the World Health Organization (WHO) for indoor residual sprays.

Methods: The larvae and pupae of Anopheles mosquitoes were sampled from multiple sites in Hainan Island, and five sites yielded sufficient mosquitoes for insecticide susceptibility bioassays. Bioassays of female adult mosquitoes three days after emergence were conducted in the two most abundant species, Anopheles sinensis and An. vagus, using three insecticides (0.05\% deltamethrin, 4\% DDT, and 5\% malathion) and following the WHO standard tube assay procedure. P450 monooxygenase, glutathione S-transferase and carboxylesterase activities were measured. Mutations at the knockdown resistance ( $k d r)$ gene and the ace-1gene were detected by DNA sequencing and PCR-RFLP analysis, respectively.
\end{abstract}

Results: An. sinensis and An. vagus were the predominant Anopheles mosquito species. An. sinensis was found to be resistant to DDT and deltamethrin. An. vagus was susceptible to deltamethrin but resistant to DDT and malathion. Low kdr mutation (L1014F) frequency (<10\%) was detected in An. sinensis, but no kdr mutation was detected in An. vagus populations. Modest to high (45\%-75\%) ace-1 mutation frequency was found in An. sinensis populations, but no ace-1 mutation was detected in An. vagus populations. Significantly higher P450 monooxygenase and carboxylesterase activities were detected in deltamethrin-resistant An. sinensis, and significantly higher P450 monooxygenase, glutathione S-transferase and carboxylesterase activities were found in malathion-resistant An. vagus mosquitoes.

Conclusions: Multiple insecticide resistance was found in An. sinensis and An. vagus in Hainan Island, a malaria-endemic area of China. Cost-effective integrated vector control programs that go beyond synthetic insecticides are urgently needed.

Keywords: Anopheles sinensis, Anopheles vagus, Insecticide resistance, Kdr mutation, Ace-1 mutation, Metabolic detoxification enzymes

\footnotetext{
* Correspondence: xgchen2001@hotmail.com

'Key Laboratory of Prevention and Control for Emerging Infectious Diseases

of Guangdong Higher Education Institutes, Department of Pathogen Biology, School of Public Health and Tropical Medicine, Southern Medical University,

Guangzhou, Guangdong 510515, China

Full list of author information is available at the end of the article
} 


\section{Background}

Malaria is a major public health problem worldwide and has significantly impeded socioeconomic development. According to the latest World Health Organization (WHO) report, since 2000 the global malaria mortality rate has decreased by $45 \%$ [1]. In China, malaria incidence has been trending downward; the total number of malaria cases was reported to be less than 3,000 in 2012 [1]. The Chinese government issued "Action Plan of China Malaria Elimination (2010-2020)," aiming at malaria elimination in China by 2020 [2,3]. Pyrethroid-impregnated bed nets and indoor residual sprays are the main components of malaria control and elimination strategy because of the high mosquito repellency of pyrethroids, insecticidal efficacy, and low toxicity to mammals [4-7]. However, extensive use of insecticides has resulted in widespread pyrethroid resistance, and insecticide resistance in malaria vectors is a growing concern in many countries. Insecticide resistance monitoring and management is a high priority in malaria control programs.

Hainan Island Province is one of two provinces in China with endemic Plasmodium falciparum malaria in China [8]; here, P. vivax malaria is also endemic. Hainan Island, separated from mainland China by the $30 \mathrm{~km}$ wide Qiongzhou Strait, has a size of $33,920 \mathrm{~km}^{2}$ and a population of 8.6 million. It has a tropical moist monsoonal climate with annual average temperature of $25^{\circ} \mathrm{C}$ and precipitation of $1500-2000 \mathrm{~mm}$. The southern part of the island is mountainous and is the most malarious region. Recent malaria incidence reports showed that 11 out of 17 counties in the southern part of the island had malaria incidence exceeding $1 / 1000[9,10]$. Major malaria vectors in Hainan Island are An. minimus and $A n$. dirus and the secondary malaria vector is An. sinensis [11-14]. Due to recent intensive malaria vector control measures, the abundance of $A n$. minimus and An. dirus has been decreasing and An. sinensis becomes increasingly important, as found in the present and other studies [11,12,14]. Although so far An. vagus has not been confirmed as a malaria vector in Hainan, An. vagus has been reported as a malaria vector in Vietnam, Laos, Cambodia $[15,16]$, Central Java (Purworejo, Kokap) and western Timor Island (Kupang) in Indonesia (P. falciparum) [17] and Bangladesh (P. falciparum and P. vivax) [18]. Chemical insecticides have been extensively used since the 1950s to control mosquito vectors, and historically, four major categories of insecticides have been sequentially applied: organochlorines, organophosphates, carbamates, and pyrethroids [19]. Pyrethroids are the most commonly used insecticides for insecticide-treated nets (ITN) and indoor residual spraying (IRS), which target indoor transmission and indoor-biting and-resting mosquitoes. Extensive use of pyrethroid insecticides has resulted in insecticide resistance, which has changed the mosquito vector community and population structures in Hainan Province. For example, An. sinensis, an exophagic and exophilic species, has now become a very important malaria vector due to its wide distribution, high density, and prevalent insecticide resistance $[11,19,20]$.

Two insecticide resistance mechanisms have been identified in mosquitoes: increased metabolic detoxification and reduced target site sensitivity [21]. Metabolic detoxification enzymes include cytochrome P450 monooxygenases (P450s), glutathione S-transferases (GSTs) and carboxylesterases (COEs). Pyrethroids and organochlorines function as neurotoxins that act by prolonging sodium channel activation, whereas organophosphates and carbamates kill insects by inhibiting acetylcholinesterase found in the central nervous system [22-24]. Target site resistance to pyrethroids and organochlorines is caused by mutations in the para-type sodium channel gene, while target site resistance to organophosphates and carbamates is caused by a mutation at codon 119 of the acetylcholinesterase (ace-1) gene. Mutations at the para-type sodium channel gene cause knockdown resistance $(k d r)$, and $k d r$ frequency has been used as an index of mosquito resistance to pyrethroids [25-27]. In $A n$. sinensis, four non-synonymous mutations at codon 1014 were reported, including L1014F [28-30], L1014C [28-30], L1014S [16,31], and L1014W [29]. In An. gambiae, the most important malaria vector in Africa, a mutation at codon N1575Y augments pyrethroid resistance [32]. On the other hand, a mutation at codon 119 of the ace-1 gene leading to a single amino acid substitution of glycine to serine in the binding pocket of acetylcholinesterase may confer resistance to organophosphates and carbamates. Mosquitoes have two acetylcholinesterase genes (ace-1 and ace-2), but only ace-1 was found to be significantly associated with insecticide resistance [33-35].

The objective of the present study was to determine the spatial heterogeneity of pyrethroid resistance in malaria vectors in Hainan Island, China. Because organochlorines and organophosphates were used for vector control and have been considered for IRS, we also determined resistance to these two classes of insecticides. We examined the frequency of $k d r$ and ace-1 mutations and analyzed metabolic detoxification enzyme activities to determine the spatial distribution of $k d r$ and $a c e-1$ mutations and to ascertain whether any molecular or biochemical biomarkers may be predictive of insecticide resistance.

\section{Methods}

\section{Mosquito sample collection}

In order to minimize the confounding effects of age and blood feeding history on insecticide resistance in fieldcollected adult mosquitoes [36], we used female adult mosquitoes reared from field-collected larvae or pupae for the resistance bioassay. Anopheles mosquito larvae 
and pupae were collected from 12 localities in Hainan Island Province, China, in July-August 2012 (Figure 1). In each locality, at least 80 aquatic habitats in rice fields were sampled using $350 \mathrm{ml}$ larval dippers. Malaria is endemic in all sites, but the southern part of the island had higher malaria incidence. Insecticides have been used extensively for agricultural pest and mosquito control. The main insecticides used in these areas include pyrethroids in mosquito coils, DDT, lambda-cyhalothrin, methothrin, permethrin, triazophos and triazophosphoxim. In each site, we collected as many mosquito larvae and pupae as possible from the rice fields. Mosquito larvae and pupae were reared to adults under local environmental conditions. Prior to insecticide assay, all adult mosquitoes were identified to species morphologically using the published morphological keys of Done 2010 [37]. Seven of the 12 sites yielded <100 Anopheles mosquitoes; therefore, insecticide resistance bioassay was not conducted due to small sample size.

\section{Mosquito insecticide susceptibility bioassay}

We used the standard WHO insecticide susceptibility tube test [27] to determine susceptibility to deltamethrin, DDT, and malathion in An. sinensis and An. vagus wherever a sufficiently large number of mosquitoes was collected. Test papers (supplied by China CDC) were $0.05 \%$ deltamethrin, $4.0 \%$ DDT, and 5\% malathion. In order to minimize the effect of mosquito age and blood feeding history on resistance, we used female adult mosquitoes three days after emergence without blood-feeding for all experiments. The susceptible control population was a laboratory $A n$. sinensis strain that has been maintained in the insectary of the Jiangsu Institute of Parasitic
Diseases in Wuxi, China, for over 10 years [30]. For each insecticide, a total of 100-200 female mosquitoes were tested with 20-25 mosquitoes per tube. Silicone oil-treated papers without insecticide (control paper) were included in the test. After a $1 \mathrm{hr}$ exposure, mosquitoes were transferred to recovery cups and maintained on $10 \%$ sucrose solution for 24 hrs. Mosquito survivorship was recorded hourly during the $24 \mathrm{hr}$ recovery period. Here we defined "resistant" as the mosquitoes that were alive 24 hours after 60-min exposure to the insecticides in the standard WHO tube bioassay, and "susceptible" as the mosquitoes that were knocked down within the 24-hr recovery period [38]. Mosquitoes were considered knocked down if they were unable to walk from the center to the border of a $7-\mathrm{cm}$ filter paper disc, either alone or when they were mechanically stimulated [39]. After the resistance/susceptible status was recorded, one leg of each mosquito was removed and preserved individually in 95\% alcohol for subsequent DNA analysis, and the remaining mosquito body was immediately tested for metabolic enzyme activities. Therefore, only fresh mosquitoes were tested for metabolic enzyme activities.

\section{Metabolic enzyme activity assays}

Three metabolic enzymes were analyzed in individual mosquitoes: cytochrome P450 monooxygenases (P450s), glutathione S-transferases (GSTs), and carboxylesterases (COEs). Measurement of P450 and GST activity followed the methods of Penilla et al. [40] and Zhong et al. [30]. COE activity was measured following the method of Hosokawa and Satoh [41]. Total protein was measured for each mosquito using the method of Bradford [42]. Mean absorbance values for each tested mosquito and



Figure 1 A map of Anopheles mosquito sampling sites in Hainan Island, China. Pie chart shows the species composition. 
enzyme were converted into enzyme activity and standardized based on the total protein amount. P450 and GST activities were calculated as pmol $7-\mathrm{HC} / \mathrm{min} / \mathrm{mg}$ protein and $\mu \mathrm{mol} \mathrm{cDNB} / \mathrm{min} / \mathrm{mg}$ protein, respectively. $\mathrm{COE}$ activity was calculated as $\mu \mathrm{mol} \mathrm{p}$-nitrophenol $/ \mathrm{min} /$ $\mathrm{mg}$ protein, using the formula ( $\Delta$ absorbance $/ \mathrm{min}-\Delta$ blank $/ \mathrm{min}) \times 1.0 / 16.4 \times 0.05 \times$ protein $(\mathrm{mg} / \mathrm{ml})$. An absorption coefficient of $16,400 \mathrm{M}^{-1} \cdot \mathrm{cm}^{-1}$ was used [43]. All measurements were done in duplicate. For each mosquito population and each insecticide, 100 adult female mosquitoes were tested. Although exposure to insecticides may alter the metabolic enzyme level, the ratio of metabolic enzyme level in the resistant mosquitoes to the susceptible mosquitoes should reflect the relative difference between resistant and susceptible individuals because the resistant and susceptible mosquitoes were both exposed to the insecticides in the same manner.

\section{Mosquito DNA extraction and molecular identification of mosquito species}

One leg of a single mosquito was used for DNA extraction with the EZNA ${ }^{\text {ma }}$ Micro Elute Genomic DNA Kit (Promega, Madison, WI). Molecular identifications of An. sinensis and An. vagus species were conducted using species-specific PCR primers (forward: TGTGAACTGC AGGACACATGAA and reverse: AGGGTCAAGGCAT ACAGAAGGC for An. sinensis; forward: CACACATC CTTGAGTGCTA and reverse: ACACATCACTTGAGG CCAC for An. vagus) to amplify the second internal transcribed spacer (ITS2) and 28S-D3 rDNA regions $[44,45]$. Amplification was performed in a $25 \mu \mathrm{L}$ reaction containing $2 \mu \mathrm{L}$ of template DNA, $2.5 \mu \mathrm{L}$ of $10 \times \mathrm{PCR}$ buffer, $0.75 \mu \mathrm{L}$ of $50 \mathrm{mM} \mathrm{MgCl}_{2}, 2 \mu \mathrm{L}$ of $2.5 \mathrm{mM}$ of each dNTP, $0.5 \mu \mathrm{L}$ of $10 \mu \mathrm{M}$ of each primer, and 0.625unit Platinum ${ }^{\circ}$ Taq DNA Polymerase (TaKaRa, China). The cycling conditions were as follows: initial denaturation at $94^{\circ} \mathrm{C}$ for $2 \mathrm{~min}, 30$ cycles of $30 \mathrm{~s}$ denaturation at $94^{\circ} \mathrm{C}$, $30 \mathrm{~s}$ annealing at $48^{\circ} \mathrm{C}$ and 30 s extension at $72^{\circ} \mathrm{C}$ followed by a final extension of $10 \mathrm{~min}$ at $72^{\circ} \mathrm{C}$. Amplification products were examined on a $2.5 \%$ agarose gel electrophoresis. The species was determined by the size of the PCR product (1,077 bp for An. sinensis and $604 \mathrm{bp}$ for An. vagus). Molecular identification was conducted for all mosquitoes subjected to insecticide resistance bioassay.

\section{Detection of $k d r$ mutation and ace-1 mutation}

To determine point mutations of the $k d r$ gene at codon 1014, we amplified a 325 bp fragment in An. sinensis and a $258 \mathrm{bp}$ fragment in An. vagus flanking the codon 1014, following the methods previously described by Zhong et al. [30] and Verhaeghen et al. [16]. The PCR product was directly sequenced from both ends using the same PCR primers by the Life Genetic Service Facility (Invitrogen, Shanghai, China). To detect point mutations of the ace-1 gene at codon 119 in An. sinensis and An. vagus, a PCR-RFLP method was used [35,46,47]. Briefly, we designed a pair of primers (forward: GTGCGACCA TGTGGAACC and reverse: ACCACGATCACGTTCTCC TC) based on the An. gambiae ace-1 gene sequence (GenBank accession: BN000066) to amplify a $193 \mathrm{bp}$ fragment that flanks the target codon position 119 in the ace-1 gene. The PCR product was digested by AluI restriction enzyme, which results in 118 bp and 75 bp fragments when there is a homozygous G119S mutation. Homozygous wildtype results in no restriction digestion (i.e., the result is a $193 \mathrm{bp}$ fragment). A total of $267 \mathrm{An}$. sinensis mosquitoes and $300 \mathrm{An}$. vagus mosquitoes were sequenced for $k d r$ and genotyped for ace-1 mutations by PCR-RFLP.

\section{Statistical analysis}

Mosquito mortality rates after the $24 \mathrm{hr}$ recovery period were calculated for each insecticide and each population. The corrected mortality rates using the Abbott's formula [48] were reported. We classified mosquito resistance status according to WHO criteria [27]: resistant if mortality is $<90 \%$, probably resistant if mortality is $90 \%-98 \%$, and susceptible if mortality is $>98 \%$. Univariate analysis of variance (ANOVA) was conducted using the arcsin transformation of the mosquito mortality rate to determine among-population differences in mosquito mortality rates in the insecticide susceptibility bioassay. One-tailed Mann-Whitney U tests were used to compare the enzyme activities between resistant and susceptible mosquitoes for each population. Chi-square tests were used to examine the association between target site mutations and the resistance phenotype.

\section{Results}

Anopheles mosquito species composition in Hainan Island A total of 10,975 Anopheles mosquito larvae and pupae were collected in the 12 sites; four sites (Ledong, Wuzhishan, Dongfang and Haikou) did not yield any collection. Among the collected mosquitoes, three species were identified based on morphological characteristics. $A n$. vagus was the predominant species in three sites: Tunchang (100\%), Dingan (100\%) and Chengmai (95\%) (Figure 1). An. sinensis was predominant in Sanya (65.2\%) and An. tessellates in Baoting (89.3\%). An. vagus and An. tessellates were also collected in three other sites (Lingao, Linshui and Wenchang), but fewer than 100 specimens were collected, and thus vector species composition was not calculated.

\section{Insecticide susceptibility bioassay and molecular identification of species}

Insecticide resistance bioassay was conducted in five mosquito populations, including An. sinensis populations 
from Sanya and Baoting and An. vagus from Tunchang, Dingan and Chengmai. Mortality rates of An. sinensis mosquitoes from Sanya and Baoting ranged from 85.8\% to $91.0 \%$ when tested against deltamethrin and from $72.7 \%$ to $78.4 \%$ against DDT, suggesting that An. sinensis was resistant to DDT and resistant or probably resistant to deltamethrin, based on the WHO criteria. Mortality rates of An. vagus mosquitoes were high (97.9\%-100\%) against deltamethrin but $<90 \%$ against DDT and malathion for the three populations tested (Chengmai, Dingan and Tunchang) (Table 1). Therefore, An. vagus mosquitoes were resistant to DDT and malathion but susceptible to deltamethrin. In general, $A n$. sinensis populations were more resistant than An. vagus to deltamethrin and DDT.

\section{Molecular species identification and $k d r$ and ace-1 allele frequencies}

We confirmed our morphological species identification by performing rDNA PCR on 267 An. sinensis and 300 $A n$. vagus mosquitoes. All mosquitoes were identified by their morphology and confirmed by molecular methods. The two methods gave consistent results. These same mosquitoes were sequenced to detect $k d r$ mutation at codon 1014 of the para-type sodium channel gene. Only one type of $k d r$ mutation (TTG to TTT) was detected at position 1014 in An. sinensis populations; this mutation leads to a change from leucine to phenylalanine (L1014F). Ten haplotypes were identified by DNA sequencing for An. sinensis (GenBank accession numbers: KF718269KF718278). No homozygous $k d r$ mutation genotype was detected. Heterozygous $k d r$ genotype was detected in resistant mosquitoes but not in susceptible mosquitoes. The frequencies of $k d r$ mutation in resistant $A n$. sinensis mosquitoes were low, ranging from 6.7\% (Baoting) to

\begin{tabular}{|c|c|c|c|c|}
\hline Insecticide & Species & $\mathbf{N}$ & Site & $\begin{array}{l}\text { Mortality }(\%) \pm \\
\text { standard error }\end{array}$ \\
\hline \multirow{4}{*}{$\begin{array}{c}0.05 \% \\
\text { Deltamethrin }\end{array}$} & \multirow[t]{2}{*}{ Anopheles sinensis } & 152 & Sanya & $85.8 \pm 6.2$ \\
\hline & & 165 & Baoting & $91.0 \pm 3.3$ \\
\hline & \multirow[t]{2}{*}{ Anopheles vagus } & 157 & Chengmai & $97.9 \pm 1.5$ \\
\hline & & 104 & Dingan & 100.0 \\
\hline \multirow[t]{5}{*}{$4 \% \mathrm{DDT}$} & \multirow[t]{2}{*}{ Anopheles sinensis } & 102 & Sanya & $78.4 \pm 7.1$ \\
\hline & & 112 & Baoting & $72.7 \pm 8.6$ \\
\hline & \multirow[t]{3}{*}{ Anopheles vagus } & 186 & Chengmai & $84.0 \pm 3.7$ \\
\hline & & 101 & Dingan & $88.8 \pm 3.2$ \\
\hline & & 88 & Tunchang & $67.1 \pm 3.3$ \\
\hline \multirow[t]{3}{*}{$5 \%$ Malathion } & \multirow[t]{3}{*}{ Anopheles vagus } & 108 & Chengmai & $88.9 \pm 1.9$ \\
\hline & & 107 & Dingan & $77.3 \pm 4.7$ \\
\hline & & 86 & Tunchang & $78.9 \pm 4.7$ \\
\hline
\end{tabular}

9.5\% (Sanya) (Table 2). Significant association was detected between $k d r$ mutation and deltamethrin or DDT resistant phenotypes $(\mathrm{P}<0.05)$ (Table 2$)$. No $k d r$ mutation was detected in either the An. vagus populations or the laboratory susceptible strain.

The same An. sinensis and An. vagus mosquitoes analyzed for $k d r$ mutations were genotyped for ace-1mutation at codon position 119 (G119S) by PCR-RFLP. DNA sequencing analysis identified 4 haplotypes in An. sinensis and 1 haplotype in An. vagus populations (GenBank accession numbers: KF718282-KF718286). The ace-1 mutation was detected in the two An. sinensis populations (Sanya and Baoting) with high frequency, ranging from $63.3 \%$ to $72.5 \%$ in resistant mosquitoes and $53.3 \%$ to $71.1 \%$ in susceptible mosquitoes. No significant association was detected between ace-1 mutation and deltamethrin and DDT resistant phenotypes $(\mathrm{P}>0.05)$ (Table 2). The ace-1 mutation was not detected in the three An. vagus populations or in the laboratory susceptible strain.

\section{Metabolic enzyme activity assays and association with resistance}

The metabolic enzyme activity ratio of resistant mosquitoes $(\mathrm{R})$ to susceptible mosquitoes (S), or R/S ratio, varied between species and among insecticides tested (Figure 2). The P450 enzyme activities were significantly higher in deltamethrin- and DDT-resistant mosquitoes in the two An. sinensis populations tested, as evidenced by $\mathrm{R} / \mathrm{S}$ ratios significantly $>1.0$. Similarly, deltamethrin-resistant mosquitoes showed significantly higher COE enzyme activities in An. sinensis. No significant change in P450, GST and $\mathrm{COE}$ activities was detected in the three An. vagus populations when tested against deltamethrin and DDT. The P450, GST and COE enzyme activities were significantly higher in two malathion-resistant An. vagus populations.

\section{Discussion}

Hainan Island is geographically isolated from the mainland of China and has been the most malarious region in China. Synthetic insecticide-based vector control is the primary malaria prevention and control method, thus determination of insecticide resistance status is paramount to the deployment of appropriate insecticides for malaria vector control. The present study surveyed the insecticide resistance status and determined the $k d r$ and ace-1 mutation frequencies in An. sinensis and $A n$. vagus in Hainan Island. We found that An. sinensis populations have developed resistance to the three classes of insecticides tested, including pyrethroid (deltamethrin), organochlorine (DDT) and organophosphate (malathion). Multiple insecticide resistance in An. sinensis suggests that the insecticide currently used for bednet impregnation and IRS may not be able to provide effective protection to 
Table 2 Kdr and ace-1 genotype and mutation frequency in Anopheles sinensis mosquitoes from Hainan Island, China

\begin{tabular}{|c|c|c|c|c|c|c|c|c|c|c|c|c|}
\hline \multirow[t]{2}{*}{ Insecticide } & \multirow[t]{2}{*}{ Population } & \multirow[t]{2}{*}{ Bioassay* } & \multirow[t]{2}{*}{$\mathbf{N}$} & \multicolumn{2}{|c|}{$K d r$ genotype } & \multirow{2}{*}{$\begin{array}{c}\mathrm{L} 1014 \mathrm{~F} \\
\text { frequency } \\
(\%)\end{array}$} & \multirow[t]{2}{*}{$\mathbf{P}$} & \multicolumn{3}{|c|}{ Ace-1genotype } & \multirow{2}{*}{$\begin{array}{c}\begin{array}{c}\text { G119S } \\
\text { frequency }\end{array} \\
(\%)\end{array}$} & \multirow[t]{2}{*}{$\mathbf{P}$} \\
\hline & & & & TTG/TTG & $\overline{\mathrm{TTG} / \mathrm{TTT}}$ & & & $\overline{\mathrm{GGC} / \mathrm{GGC}}$ & GGC/AGC & $\overline{A G C / A G C}$ & & \\
\hline \multirow[t]{4}{*}{$0.05 \%$ Deltamethrin } & Sanya & Resistant & 20 & 17 & 3 & 7.5 & 0.041 & 0 & 11 & 9 & 72.5 & 1.000 \\
\hline & & Susceptible & 47 & 47 & 0 & 0 & & 1 & 26 & 20 & 70.2 & \\
\hline & Baoting & Resistant & 15 & 13 & 2 & 6.7 & 0.090 & 2 & 7 & 6 & 63.3 & 0.435 \\
\hline & & Susceptible & 48 & 48 & 0 & 0 & & 10 & 21 & 17 & 57.3 & \\
\hline \multirow[t]{4}{*}{$4 \% \mathrm{DDT}$} & Sanya & Resistant & 21 & 17 & 4 & 9.5 & 0.027 & 0 & 13 & 8 & 69.0 & 1.000 \\
\hline & & Susceptible & 38 & 38 & 0 & 0 & & 1 & 20 & 17 & 71.1 & \\
\hline & Baoting & Resistant & 32 & 27 & 5 & 7.8 & 0.024 & 7 & 9 & 16 & 64.1 & 0.238 \\
\hline & & Susceptible & 46 & 46 & 0 & 0 & & 13 & 17 & 16 & 53.3 & \\
\hline
\end{tabular}

* "Resistant" refers to the mosquitoes that were alive 24 hours after 60-min exposure to the insecticides in the standard WHO tube bioassay; and "susceptible" refers to the mosquitoes that were knocked down within the 24-hr recovery period. Significant $p$-values $(p<0.05)$ are given in bold type.

humans from parasite-carrying mosquitoes. Further examination of the resistance mechanism indicated that the mutation frequency of the $k d r$ target site (L1014F) was significantly associated with deltamethrin and DDT resistance, and P450 and COE enzyme activities may also play an important role in An. sinensis. An. vagus was susceptible to deltamethrin but resistant to DDT and malathion. Interestingly, no $k d r$ or ace-1 mutations were detected in the 300 An. vagus specimens we analyzed. Elevated P450, GST and COE enzyme activities were found in malathionresistant An. vagus, suggesting that metabolic resistance is the major resistance mechanism. However, it is also possible that this mosquito species exhibits behavioral avoidance to insecticides. Behavioral responses of mosquitoes to DDT and pyrethroids have been previously reported in An. vagus [49].

There have been debates in the literature over whether $k d r$ frequency may be used as a biomarker for deltamethrin resistance [50,51]. In the two An. sinensis populations examined in the present study, we found that $k d r$ frequency was significantly associated with the deltamethrinresistant phenotype, and no L1014F allele was found in the susceptible individuals. Whether $k d r$ frequency can predict deltamethrin resistance at the population level may be contingent on a number of factors, such as $k d r$ frequency and the relative importance of metabolic resistance. The two $A n$. sinensis populations examined here exhibited a low $k d r$ mutation frequency $(<10 \%)$, suggesting prevalent mutations in the $k d r$ target gene. In central Chinese provinces such as Hunan, Hubei, Jiangsu and Anhui, $k d r$ frequency in $A n$. sinensis was very high (>90\%) and $k d r$ allele frequency had no predictive power of deltamethrin resistance $[29,30]$. On the other hand, $k d r$ allele frequency had no predictive power when the populations completely lacked $k d r$ mutations, as in the An. sinensis populations in Yunnan province [30]. Similar phenomena were found in An. gambiae and An. arabiensis mosquitoes in Africa, where $k d r$ frequency was not significantly associated with pyrethroid resistance when $k d r$ frequency was high [52,53], or when $k d r$ mutation was completely lacking in the population [54].

Four types of $k d r$ mutations (L1014F, L1014C, L1014S, and L1014W) have been reported in An. sinensis mosquitoes [16,28-31] and two types (L1014F and L1014S) in An. vagus $[16,55]$. Low frequencies of L1014F $k d r$ allele in the heterozygous state were found in An. sinensis mosquito populations examined in our study. Such a low diversity of $k d r$ mutations in Hainan Island mosquito populations may result from the geographic isolation of the island, which may prevent $k d r$ mutations from being introduced to Hainan. Further study is needed to examine the genetic structure of An. sinensis populations in mainland China and Hainan Island to determine the role of gene flow in the spread of $k d r$ mutations.

We did not detect any $k d r$ or ace-1 mutationsin $A n$. vagus populations, which suggests either that $A n$. vagus lacks mutations at the target sites of insecticides or that the mutation frequency was extremely low. The lack of mutations at the target sites of insecticides in An. vagus was not unique to our particular study sites. For example, a survey of An. vagus from 42 sites in Vietnam, Laos, and Cambodia did not detect $k d r$ mutations in 35 sites, and the remaining 7 sites exhibited very low $k d r$ frequencies [16]. Given the absence of mutations at the insecticide target sites, metabolic resistance becomes the major resistance mechanism. In the present study, we found significantly higher P450, GST and COE enzyme activities in malathion-resistant $A n$. vagus individuals and significantly higher P450 and COE enzyme activities in deltamethrinresistant $A n$. sinensis. These results suggest that metabolic detoxification mechanisms were widespread in An. sinensis and $A n$. vagus populations from Hainan Island. We want to note that all mosquito samples used for detoxification enzyme activity were pre-exposed to insecticide. It is possible that resistant and susceptible mosquitoes may exhibit differential responses to pre-exposure to insecticides in 


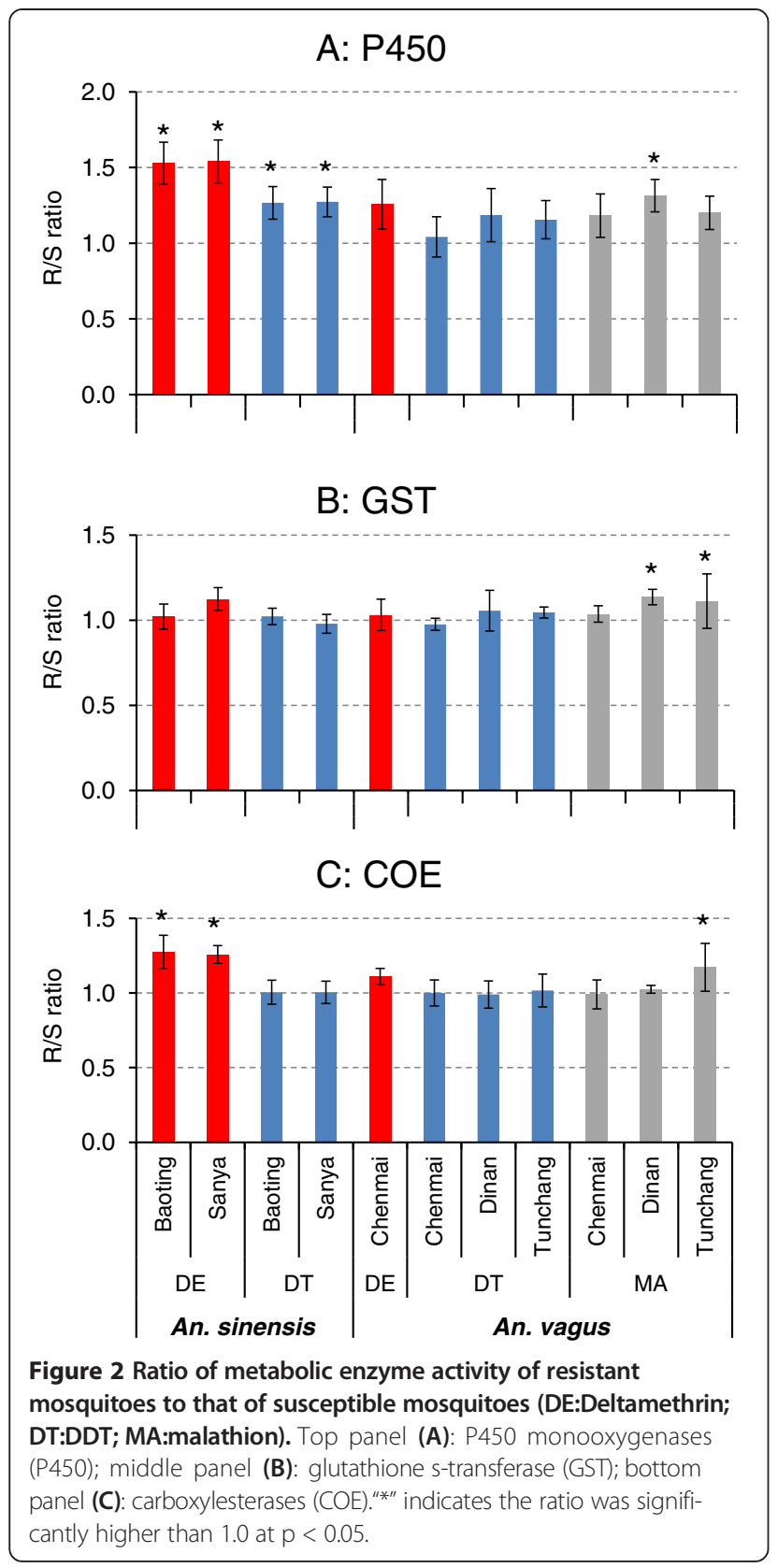

their detoxification enzyme activities. Therefore, our experimental procedure may potentially lead to skewing of $\mathrm{R} / \mathrm{S}$ ratio.

Resistance to multiple classes of insecticides is becoming a common problem in various malaria vector species. Reported multiple resistance in malaria vectors includes An. gambiae [46,56-58], An. arabiensis [47], and An. funestus [59] in Africa, and An. culicifacies, An. subpictus, An. nigerrimus, and An. peditaeniatus [60] in Asia. Multiple insecticide resistance impedes the effectiveness of front-line malaria vector control programs, which are primarily based on the use of pyrethroids. These control programs have led to major changes in vectorial systems, including vector species composition as well as early biting behaviors and increased insecticide resistance in the past decade [61,62]; consequently, outdoor transmission has increased [63]. Considering the prevailing resistance to pyrethroids and organophosphates, the choice for synthetic insecticides is limited. Integrated vector control programs that go beyond synthetic insecticides but remain cost effective are urgently needed. Promising methods include larval source reduction through ecological or environmental manipulation [64,65], house modification [66], biopesticides [67], and long-lasting microbial insecticides [68]. Vector control tools with a long-lasting efficacy would help maintain the cost-effectiveness of the control program.

\section{Conclusion}

This study found multiple insecticide resistance in $A n$. sinensis and An. vagus in Hainan Island, a malariaendemic area of China. Low $k d r$ mutation frequency and modest ace-1 mutation frequency were found in $A n$. sinensis. $K d r$ frequency was significantly associated with deltamethrin resistance in An. sinensis, and significantly higher metabolic enzyme activities were found in resistant mosquitoes, suggesting that target-site insensitivity and metabolic resistance both play important roles in insecticide resistance in An. sinensis. In An. vagus, the absence of $k d r$ and ace-1 mutations and significantly higher P450, GST, and COE enzyme activities in malathion-resistant mosquitoes suggest that metabolic resistance is the major resistance mechanism. Cost-effective integrated vector control programs that go beyond synthetic insecticides are urgently needed.

\section{Competing interests}

The authors declare that they have no competing interests.

\section{Authors' contributions}

All the authors have contributed significantly to this study. Conceived and designed the experiments: XGC and LC. Performed the experiments: QQ, YL, DZ, NZ and CL. Analyzed the data: QQ, DZ and GY. Wrote and revised the manuscript: QQ, DZ, GY, XC. All authors read and approved the final manuscript.

\section{Acknowledgements}

We thank Guohui Yi and Hong Guo of Hainan Medical College for their assistance with mosquito collection and Guofa Zhou of the University of California, Irvine for assistance with statistical analysis. This work is supported by grants from the National Institutes of Health (R01Al083202, R03 TW008940; D43 TW009527) and Emerging Infectious Disease Prevention and Control Key Laboratory of Guangdong Provincial Higher Education (KLB09007).

\section{Author details}

${ }^{1}$ Key Laboratory of Prevention and Control for Emerging Infectious Diseases of Guangdong Higher Education Institutes, Department of Pathogen Biology, School of Public Health and Tropical Medicine, Southern Medical University, Guangzhou, Guangdong 510515, China. ${ }^{2}$ Department of Parasitology, Wenzhou Medical University, Wenzhou 325035, China. ${ }^{3}$ Program in Public Health, College of Health Sciences, University of California at Irvine, Irvine, CA 92697, USA. ${ }^{4}$ Department of Entomology, Pennsylvania State University, State College, University Park, PA 16802, USA. 
Received: 2 February 2014 Accepted: 27 February 2014

Published: 3 March 2014

\section{References}

1. WHO: World malaria report. Geneva, Switzerland: World Health Organization; 2013. Available at: http://www.who.int/malaria/publications/world_malaria_ report_2013/report/en/. webcite. Accessed February 28, 2014.

2. Ministry of Health: Action plan of China malaria elimination (2010-2020). Beijing: Ministry of Health of the People's Republic of China; 2010. Available at: http:/whothailand.healthrepository.org/bitstream/123456789/1460/1/ Action\%20Plan\%20of\%20China\%20\%20Malaria\%20Elimination\%20_20102020_.pdf. webcite. Accessed February 28, 2014.

3. Yin JH, Yang MN, Zhou SS, Wang Y, Feng J, Xia ZG: Changing malaria transmission and implications in China towards National Malaria Elimination Programme between 2010 and 2012. PLoS One 2013, 8(9):e74228.

4. Coosemans M, Carnevale P: Malaria vector control: a critical review on chemical methods and insecticides. Ann Soc Belg Med Trop 1995, 75(1):13-31.

5. Liu N, Xu Q, Zhu F, Zhang LEE: Pyrethroid resistance in mosquitoes. Insect Sci 2006, 13(3):159-166

6. Reigart JR, Roberts JR: Recognition and management of pesticide poisonings. 5th edition. EPA \#735-R-98-003. U.S. Environmental Protection Agency; 1999:34-74.

7. WHO: Global Plan for Insecticide Resistance Management in Malaria Vectors. Geneva, Switzerland: World Health Organization; 2012. Available at: http:/www.who.int/malaria/publications/atoz/gpirm/en/. webcite. Accessed February 28, 2014.

8. WHO: World malaria report 2010. Geneva, Switzerland: World Health Organization; 2010. Available at: http://www.who.int/malaria/world_malaria_ report_2010/en/. webcite. Accessed February 28, 2014.

9. Lin H, Lu L, Tian L, Zhou S, Wu H, Bi Y, Ho S, Liu Q: Spatial and temporal distribution of falciparum malaria in China. Malar J 2009, 8(1):130.

10. Sheng HF, Zhou SS, Gu ZC, Zheng X: Malaria situation in the People's Republic of China in 2002. Zhongguo Ji Sheng Chong Xue Yu Ji Sheng Chong Bing Za Zhi 2003, 21(4):193-196.

11. Chow C-Y: Malaria vector in China. Chinese J Entomol Special Publ 1991, 6:67-79.

12. Cai XZ: Malaria control in Hainan Island during the past 40 years. Hainan Med J 1993, 4(3):1-3 (in Chinese with English abstract).

13. Lu BL: Prevalence of malaria and vector research in China. Lit Inf Prev Med 2001, 7(1):98-100 (in Chinese with English abstract).

14. Zeng LH, Wang SQ, Sun DW, Zhao W, Li SG, Yang X: Resistance assay of malaria vectors to four kinds of common insecticides in some endemic areas of Hainan Province. Zhongguo Ji Sheng Chong Xue Yu Ji Sheng Chong Bing Za Zhi 2011, 29(3):200-203.

15. Rueda LM, Pecor JE, Harrison BA: Updated distribution records for Anopheles vagus (Diptera: Culicidae) in the Republic of Philippines, and considerations regarding its secondary vector roles in Southeast Asia. Trop Biomed 2011, 28(1):181-187.

16. Verhaeghen K, Van Bortel W, Trung H, Sochantha T, Keokenchanh K, Coosemans M: Knockdown resistance in Anopheles vagus, An. sinensis, An. paraliae and An. peditaeniatus populations of the Mekong region. Parasit Vectors 2010, 3(1):59.

17. Elyazar IR, Sinka ME, Gething PW, Tarmidzi SN, Surya A, Kusriastuti R, Winarno Baird JK, Hay SI, Bangs MJ: The distribution and bionomics of Anopheles malaria vector mosquitoes in Indonesia. Adv Parasitol 2013, 83:173-266.

18. Alam MS, Khan MG, Chaudhury N, Deloer S, Nazib F, Bangali AM, Haque R: Prevalence of anopheline species and their Plasmodium infection status in epidemic-prone border areas of Bangladesh. Malar J 2010, 9:15.

19. Liu Y, Zhang H, Qiao C, Lu X, Cui F: Correlation between carboxylesterase alleles and insecticide resistance in Culex pipiens complex from China. Parasit Vectors 2011, 4(236).

20. Pan J-Y, Zhou S-S, Zheng X, Huang F, Wang D-Q, Shen Y-Z, Su Y-P, Zhou G-C, Liu F, Jiang J-J: Vector capacity of Anopheles sinensis in malaria outbreak areas of central China. Parasit Vectors 2012, 5(1):136.

21. Hemingway J, Hawkes NJ, McCarroll L, Ranson H: The molecular basis of insecticide resistance in mosquitoes. Insect Biochem Mol Biol 2004, 34(7):653-665.
22. Hemingway J, Georghiou GP: Studies on the acetylcholinesterase of Anopheles albimanus resistant and susceptible to organophosphate and carbamate insecticides. Pestic Biochem Physiol 1983, 19(2):167-171.

23. Kamel F, Hoppin JA: Association of pesticide exposure with neurologic dysfunction and disease. Environ Health Perspect 2004, 112(9):950-958.

24. Soderlund DM, Bloomquist JR: Neurotoxic actions of pyrethroid insecticides. Annu Rev Entomol 1989, 34:77-96.

25. Martinez-Torres D, Chandre F, Williamson MS, Darriet F, Berge JB, Devonshire AL, Guillet P, Pasteur N, Pauron D: Molecular characterization of pyrethroid knockdown resistance $(\mathrm{kdr})$ in the major malaria vector Anopheles gambiae s.s. Insect Mol Biol 1998, 7(2):179-184.

26. Ranson H, Jensen B, Vulule JM, Wang X, Hemingway J, Collins FH: Identification of a point mutation in the voltage-gated sodium channel gene of Kenyan Anopheles gambiae associated with resistance to DDT and pyrethroids. Insect Mol Biol 2000, 9(5):491-497.

27. WHO: Test procedures for insecticide resistance monitoring in malaria vector mosquitoes. Geneva, Switzerland: World Health Organization; 2013. Available at: http:/www.who.int/malaria/publications/atoz/9789241505154/en/. webcite. Accessed February 28, 2014.

28. Kang S, Jung J, Lee S, Hwang H, Kim W: The polymorphism and the geographical distribution of the knockdown resistance ( $k d r)$ of Anopheles sinensis in the Republic of Korea. Malar J 2012, 3(11):151.

29. Tan W-L, Wang Z-M, Li C-X, Chu H-L, X Y Y, Dong Y-D, Wang Z-C, Chen D-Y, Liu H, Liu D-P, Liu N, Sun J, Zhao T: First report on co-occurrence knockdown resistance mutations and susceptibility to beta-cypermethrin in Anopheles sinensis from Jiangsu Province, China. PLOS ONE 2012, 7(1):e29242.

30. Zhong D, Chang X, Zhou G, He Z, Fu F, Yan Z, Zhu G, Xu T, Bonizzoni M, Wang M-H, Cui L, Zheng B, Chen B, Yan G: Relationship between knockdown resistance, metabolic detoxification and organismal resistance to pyrethroids in Anopheles sinensis. PLOS ONE 2013, 8(2):e55475.

31. Tan $W L$, Li CX, Wang ZM, Liu MD, Dong YD, Feng XY, Wu ZM, Guo XX, Xing D, Zhang YM, Wang ZC, Zhao TY: First detection of multiple knockdown resistance $(k d r)$-like mutations in voltage-gated sodium channel using three new genotyping methods in Anopheles sinensis from Guangxi Province, China. J Med Entomol 2012, 49(5):1012-1020,

32. Jones CM, Liyanapathirana M, Agossa FR, Weetman D, Ranson H, Donnelly MJ, Wilding CS: Footprints of positive selection associated with a mutation (N1575Y) in the voltage-gated sodium channel of Anopheles gambiae. Proc Natl Acad Sci U S A 2012, 109(17):6614-6619.

33. Essandoh J, Yawson A, Weetman D: Acetylcholinesterase (Ace-1) target site mutation $119 \mathrm{~S}$ is strongly diagnostic of carbamate and organophosphate resistance in Anopheles gambiae s.s. and Anopheles coluzzii across southern Ghana. Malar J 2013, 12(1):404.

34. Weill M, Fort P, Berthomieu A, Dubois MP, Pasteur N, Raymond M: A novel acetylcholinesterase gene in mosquitoes codes for the insecticide target and is non-homologous to the ace gene in Drosophila. Proc Biol Sci 2002, 269(1504):2007-2016.

35. Weill M, Malcolm C, Chandre F, Mogensen K, Berthomieu A, Marquine M, Raymond $\mathrm{M}$ : The unique mutation in ace-1 giving high insecticide resistance is easily detectable in mosquito vectors. Insect Mol Biol 2004, 13(1):1-7.

36. Xu T, Zhong D, Chang X, Hemingway J, Fu F, Yan G, Zheng B: Anopheles sinensis mosquito insecticide resistance: comparison of three mosquito sample preparation methods in resistance measurements. Parasit Vectors 2014, 1. in press.

37. Dong X: The Mosquito Fauna of Yunnan (Volumes one), Volume 1. Kunming: Yunnan Publishing Group Corporation, Yunnan Science \& Technology Press; 2010.

38. Bonizzoni M, Afrane Y, Dunn WA, Atieli FK, Zhou G, Zhong D, Li J, Githeko A, Yan G: Comparative transcriptome analyses of deltamethrin-resistant and -susceptible Anopheles gambiae mosquitoes from Kenya by RNA-Seq. PLOS ONE 2012, 7(9):e44607.

39. Gonzalez Audino P, Vassena C, Barrios S, Zerba E, Picollo Ml: Role of enhanced detoxication in a deltamethrin-resistant population of Triatoma infestans (Hemiptera, Reduviidae) from Argentina. Mem Inst Oswaldo Cruz 2004, 99(3):335-339.

40. Penilla PR, RodríGuez AD, Hemingway J, Torres JL, Arredondo-JimÉNez JI, RodríGuez MH: Resistance management strategies in malaria vector mosquito control: baseline data for a large-scale field trial against Anopheles albimanus in Mexico. Med Vet Entomol 1998, 12(3):217-233. 
41. Hosokawa M, Satoh T: Measurement of carboxylesterase (CES) activities. Curr Protoc Toxicol 2002, Suppl 10:4.7.14. 4.7.14

42. Bradford MM: A rapid and sensitive method for the quantitation of microgram quantities of protein utilizing the principle of protein-dye binding. Anal Biochem 1976, 72(1-2):248-254.

43. Enholm C, Kuusi T: Preparation, characterization, and measurement of hepatic lipase. Methods Enzymol 1986, 129:717-738.

44. Joshi D, Park MH, Saeung A, Choochote W, Min GS: Multiplex assay to identify Korean vectors of malaria. Mol Ecol Resour 2010, 10(4):748-750.

45. Zomuanpuii R, Ringngheti L, Brindha S, Gurusubramanian G, Senthil Kumar $\mathrm{N}$ : ITS2 characterization and Anopheles species identification of the subgenus Cellia. Acta Trop 2012, 125(3):309-319.

46. Namountougou M, Simard F, Baldet T, Diabate A, Ouedraogo JB, Martin T, Dabire RK: Multiple insecticide resistance in Anopheles gambiae s.l: populations from Burkina Faso, West Africa. PLOS ONE 2012, 7(11):e48412.

47. Yewhalaw D, Wassie F, Steurbaut W, Spanoghe P, Van Bortel W, Denis L, Tessema DA, Getachew Y, Coosemans M, Duchateau L, Speybroeck N: Multiple insecticide resistance: an impediment to insecticide-based malaria vector control program. PLOS ONE 2011, 6(1):e16066.

48. Abbott WS: A method of computing the effectiveness of an insecticide. J Econ Entomol 1925, 18(2):265-267.

49. Chareonviriyaphap T, Bangs M, Suwonkerd W, Kongmee M, Corbel V, Ngoen-Klan R: Review of insecticide resistance and behavioral avoidance of vectors of human diseases in Thailand. Parasit Vectors 2013, 6:280.

50. Brooke BD: $k d r$ : can a single mutation produce an entire insecticide resistance phenotype? Trans R Soc Trop Med Hyg 2008, 102(6):524-525.

51. Donnelly MJ, Corbel V, Weetman D, Wilding CS, Williamson MS, Black WCT: Does kdr genotype predict insecticide-resistance phenotype in mosquitoes? Trends Parasitol 2009, 25(5):213-219.

52. Protopopoff N, Matowo J, Malima R, Kavishe R, Kaaya R, Wright A, West P, Kleinschmidt I, Kisinza W, Mosha F, Rowland M: High level of resistance in the mosquito Anopheles gambiae to pyrethroid insecticides and reduced susceptibility to bendiocarb in north-western Tanzania. Malar J 2013, 12(1):149.

53. Yewhalaw D, Bortel WV, Denis L, Coosemans M, Duchateau L, Speybroeck N: First evidence of high knockdown resistance frequency in Anopheles arabiensis (Diptera: Culicidae) from Ethiopia. Am J Trop Med Hyg 2010, 83(1):122-125

54. Mouatcho JC, Munhenga G, Hargreaves K, Brooke BD, Coetzee M, Koekemoer LL: Pyrethroid resistance in a major African malaria vector Anopheles arabiensis from Mamfene, northern KwaZulu-Natal, South Africa. S Afr J Sci 2009, 105:127-131.

55. Syafruddin D, Hidayati A, Asih P, Hawley W, Sukowati S, Lobo N: Detection of $1014 \mathrm{~F} \mathrm{kdr} \mathrm{mutation} \mathrm{in} \mathrm{four} \mathrm{major} \mathrm{Anopheline} \mathrm{malaria} \mathrm{vectors} \mathrm{in}$ Indonesia. Malar J 2010, 9(1):315.

56. Corbel V, N'Guessan R, Brengues C, Chandre F, Djogbenou L, Martin T, Akogbeto M, Hougard JM, Rowland M: Multiple insecticide resistance mechanisms in Anopheles gambiae and Culex quinquefasciatus from Benin, West Africa. Acta Trop 2007, 101(3):207-216.

57. Edi CV, Koudou BG, Jones CM, Weetman D, Ranson H: Multiple-insecticide resistance in Anopheles gambiae mosquitoes: Southern Cote d'Ivoire. Emerg Infect Dis 2012, 18(9):1508-1511.

58. Kwiatkowska RM, Platt N, Poupardin R, Irving H, Dabire RK, Mitchell S, Jones CM, Diabate A, Ranson H, Wondji CS: Dissecting the mechanisms responsible for the multiple insecticide resistance phenotype in Anopheles gambiae s.s., M form, from Vallee du Kou, Burkina Faso. Gene 2013, 519(1):98-106.

59. Djouaka R, Irving H, Tukur Z, Wondji CS: Exploring mechanisms of multiple insecticide resistance in a population of the malaria vector Anopheles funestus in Benin. PLOS ONE 2011, 6(11):e27760.

60. Perera M, Hemingway J, Karunaratne SHPP: Multiple insecticide resistance mechanisms involving metabolic changes and insensitive target sites selected in anopheline vectors of malaria in Sri Lanka. Malar J 2008, 7(1):168

61. Moiroux N, Gomez MB, Pennetier CD, Elanga E, DjÃ "nontin A, Chandre F, DjÃ̈"gbã@ I, Guis H, Corbel V: Changes in Anopheles funestus biting behavior following universal coverage of long-lasting insecticidal nets in Benin. J Infect Dis 2012, 206(10):1622-1629.

62. Russell TL, Beebe NW, Cooper RD, Lobo NF, Burkot TR: Successful malaria elimination strategies require interventions that target changing vector behaviours. Malar J 2013, 12(56)
63. Govella NJ, Ferguson $\mathrm{H}$ : Why use of interventions targeting outdoor biting mosquitoes will be necessary to achieve malaria elimination. Front Physiol 2012, 3:199.

64. Okumu FO, Govella NJ, Moore SJ, Chitnis N, Killeen GF: Potential benefits, limitations and target product-profiles of odor-baited mosquito traps for malaria control in Africa. PLOS ONE 2010, 5(7):e11573.

65. Imbahale S, Githeko A, Mukabana W, Takken W: Integrated mosquito larval source management reduces larval numbers in two highland villages in western Kenya. BMC Public Health 2012, 12(1):362.

66. Gunawardena DM, Wickremasinghe AR, Muthuwatta L, Weerasingha $S$, Rajakaruna J, Senanayaka T, Kotta PK, Attanayake N, Carter R, Mendis KN: Malaria risk factors in an endemic region of Sri Lanka, and the impact and cost implications of risk factor-based interventions. Am J Trop Med Hyg 1998, 58(5):533-542.

67. Kamareddine L: The biological control of the malaria vector. Toxins 2012, 4(9):748-767.

68. Grewal PS: Factors in the success and failure of microbial control in turfgrass. Integr Pest Manag Rev 1999, 4(4):287-294.

doi:10.1186/1756-3305-7-92

Cite this article as: Qin et al:: Insecticide resistance of Anopheles sinensis and An. vagus in Hainan Island, a malaria-endemic area of China.

Parasites \& Vectors 2014 7:92.

\section{Submit your next manuscript to BioMed Central and take full advantage of:}

- Convenient online submission

- Thorough peer review

- No space constraints or color figure charges

- Immediate publication on acceptance

- Inclusion in PubMed, CAS, Scopus and Google Scholar

- Research which is freely available for redistribution

Submit your manuscript at www.biomedcentral.com/submit
C Biomed Central 